\title{
ARMC5 MUTATION IN A FAMILY WITH CUSHING SYNDROME DUE TO BILATERAL MACRONODULAR ADRENAL HYPERPLASIA
}

Teresa Rego ${ }^{1}$, Fernando Fonseca ${ }^{1}$, Ana Agapito ${ }^{1}$, Stéphanie Espiard ${ }^{2}$, Karine Perlemoine ${ }^{2}$, Jérôme Bertherat ${ }^{2}$

${ }^{1}$ Endocrinology Department, Hospital Curry Cabral, CHLC - Lisbon, Portugal

${ }^{2}$ Endocrinology Department, Hôpital Cochin - Paris, France

\section{INTRODUCTION}

$\square$ Bilateral Macronodular Adrenal Hyperplasia (BMAH) is a rare and insidious etiology of Cushing's syndrome (CS).

$\square \mathrm{BMAH}$ is usually characterized by functioning adrenal macronodules and variable cortisol secretion.

$\square$ The asymmetric/asynchronous involvement of only one adrenal gland can also occur, making disease diagnosis a challenge.

$\square$ Familial clustering suggests a genetic cause that was recently confirmed, after identification of inactivating germline mutations in armadillo repeat containing 5 (ARMC5) gene.

\section{CLINICAL CASE}

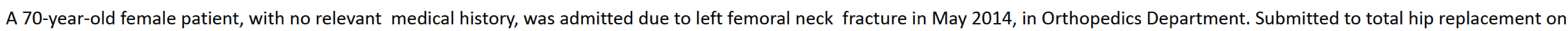
20/05/2014. During hospitalization hypertension (HTA) and hypokalemia were diagnosed, both difficult to control.

PHYSICAL EXAMINATION

-Thin and dry skin with multiple bruises Rubeosis and moon-like face

Central obesity

Weight: $75 \mathrm{Kg}$

Height: $1.57 \mathrm{~m}$

BMI: $30 \mathrm{Kg} / \mathrm{m} 2$

Severe muscular atrophy

\section{Admitted to the ENDOCRINOLOGY DEPARTMENT for suspected CUSHING SYNDROME}
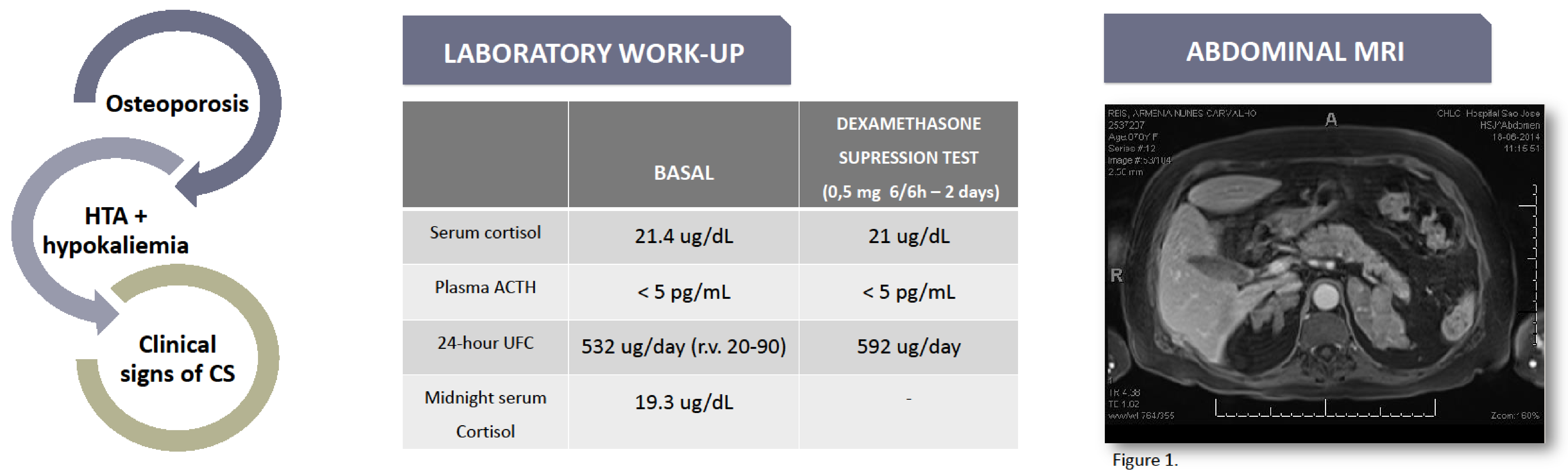

Right gland:

$55 \times 54 \times 30 \mathrm{~mm}$

Left gland:

$85 \times 53 \times 35 \mathrm{~mm}$

Overt Cushing syndrome

BILATERAL MACRONODULAR ADRENAL HYPERPLASIA

\section{TREATMENT}

\section{- BILATERAL ADRENALECTOMY (July/2014)}

- Right gland weight $62 \mathrm{~g}$ (Fig. 2)

Left gland weight $151 \mathrm{~g}$ (Fig. 3)

- Pathology - Cortical nodular hyperplasia

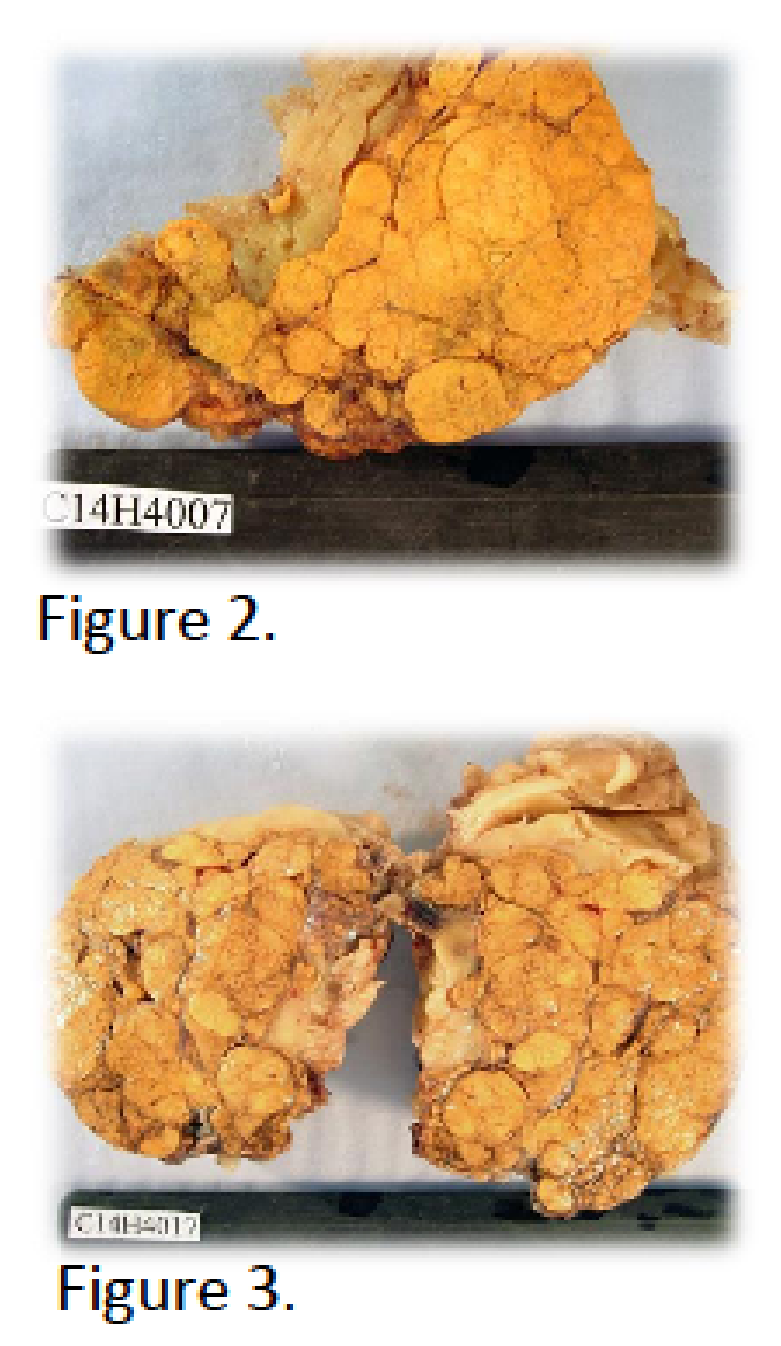

\section{FAMILY HISTORY}

In 2006 this patient's 39-year-old daughter had been observed by one of the authors . Severe clinical hypercortisolism

ACTH $<5$ pg/ml; UFC - 204 ug/24h; serum cortisol after low dose DST - 16.2 ug/dl ;

Abdominal CT scan: bilateral enlarged nodular adrenals with maximal axis of $15 \mathrm{~cm}$

for both.

BILATERAL ADRENALECTOMY (right gland - 68g; left gland - 104g)

Pathology - Cortical nodular hyperplasia.
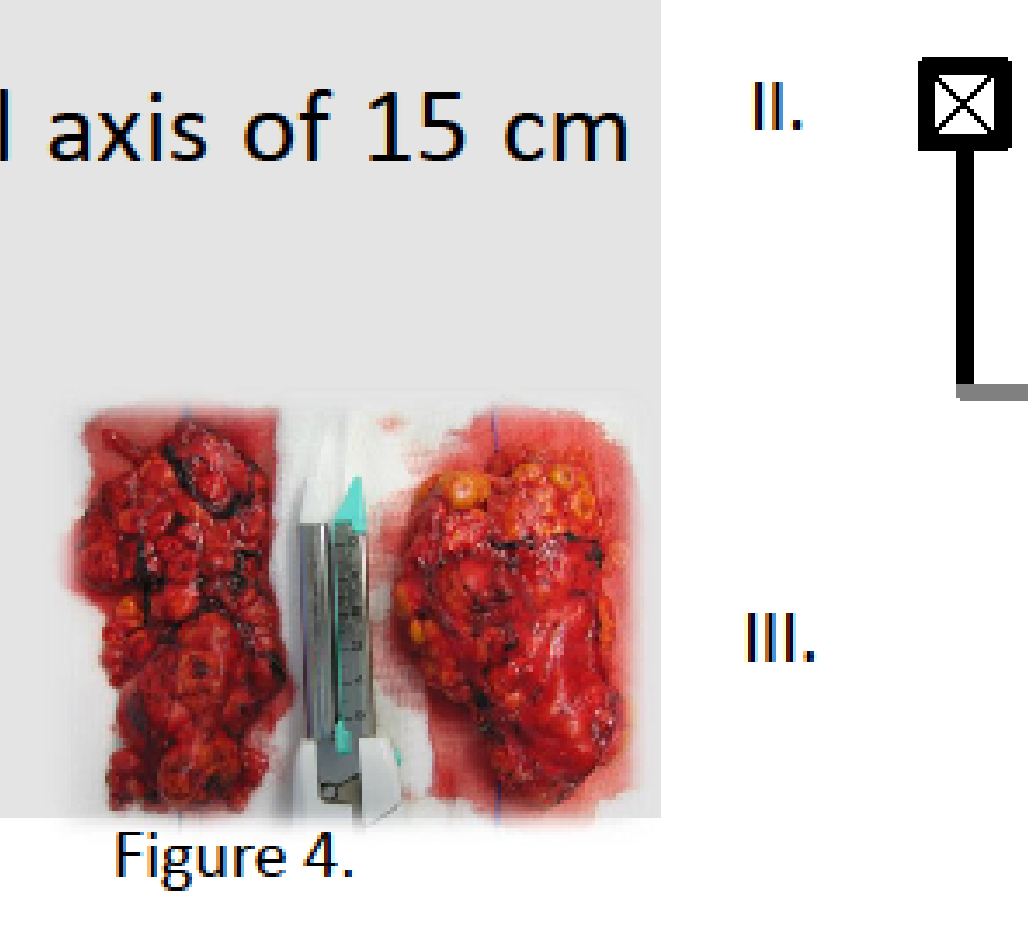

In this family context of severe bilateral disease, genetic study was performed.

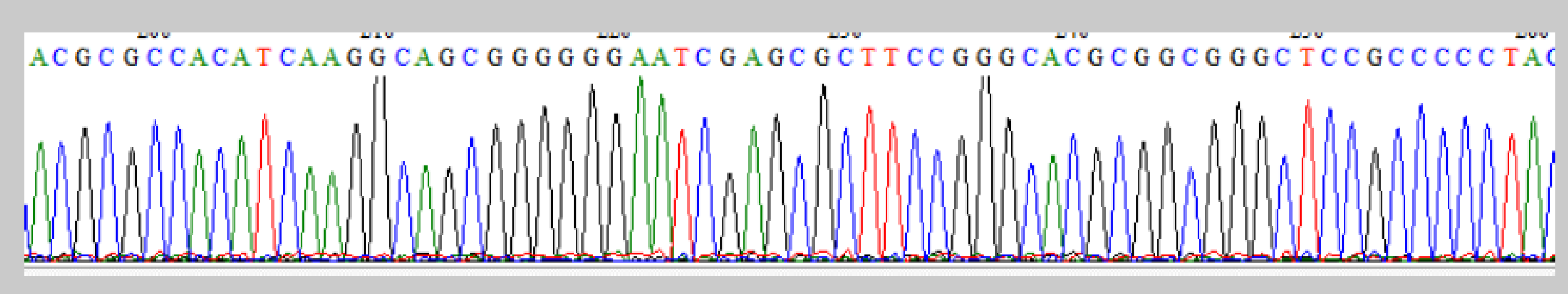

Leucocyte DNA genotyping identified in both patients an ARMC5 mutation in exon 1 (c.172_173insA p.158Nfs*44)

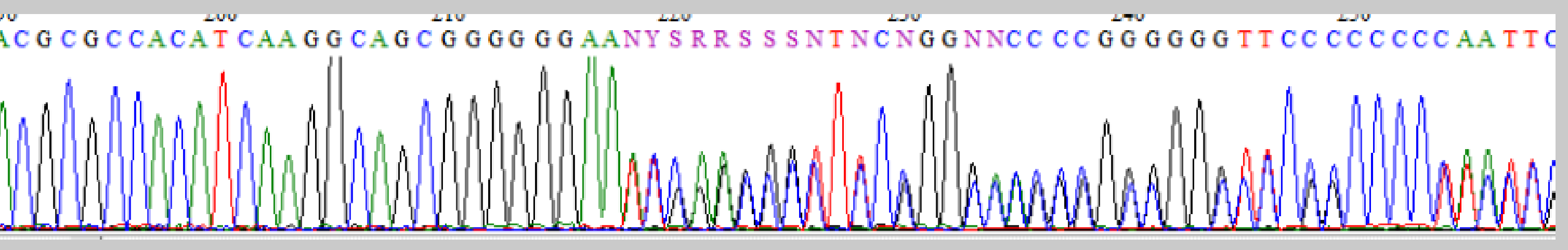

\section{COMMENTS}

$\checkmark$ The clinical cases herein described have an identical phenotype with severe hypercortisolism and huge adrenal glands, but different ages on diagnosis.

$\checkmark$ Current knowledge of inheritance of this disease, its insidious nature and the well known deleterious effect of hypercortisolism favor genetic study of other family members

$\checkmark$ Since ARMC5, a tumoral suppressor gene, is expressed in many organs and recent findings suggest an association of BMAH and meningeoma, a watchful follow-up is required.

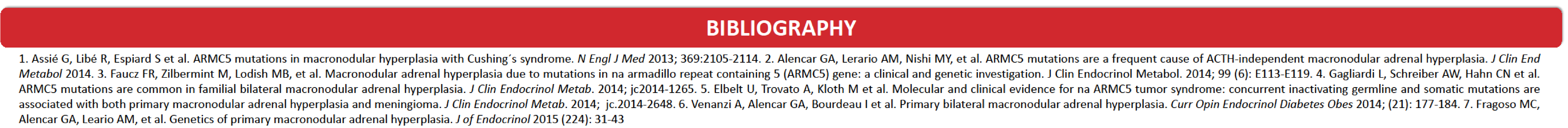

\section{(4216-EP}

ت 